\title{
Virtual Desktop Deployment in Middle Education and Community Centers Using Low-Cost Hardware
}

\author{
Muñoz-Arcentales José, Zambrano-Vite Sara, and Marin-Garcia Ignacio
}

\begin{abstract}
In Ecuador most children are unable to access basic computer education because they attend schools that don't have the budget to implement computer laboratories. A proposed solution is to use desktop virtualization to provide basic computer services (such as web browsing, email and office tools) to schools and community centers, without new equipment investment. Desktop Virtualization allows reusing existing hardware and saves in electrical consumption and licensing. Using virtual desktop technologies allowed us to reuse the schools existing hardware saving the school limited resources while providing a centralized environment of fast and efficient administration. By implementing open source of imatic tools, even more saving were possible, and at the same time, we were able to align the schools policies with the open source national government initiative. One final benefit was that the low performance hardware we used on the student side had lower power consumption than specialized equipment, and because of it, we could help the sustainability national requirements. In order to measure user's requirements and satisfaction, polls were performed in different middle schools in Manabí (Ecuadorian coast province). These pools also helped us to determine which computer tools the students were using; and allowed us to elaborate some test environments for the hardware performance.
\end{abstract}

Index Terms-Desktop virtualization, school, open source, LTSP.

\section{INTRODUCTION}

In Ecuador, the education has been, until recently, based in a formal education environment using books and with a teacher giving lectures that the students should absorb. With this educational method, the children lose the opportunity of growing up in an advanced technological environment that would open the door to a new globalized and integrated world. However due to the political change in Ecuador and the related legal environment with a Constitution that dictates that "All the people, individual, or by group have the right to information and communication technologies universal access" [1] technology education has become a required subject to study. The new education schema is expected to improve the student's academic experience and performance and at the same time it facilitates the learning process saving time and effort. This major technological change has been recognized by governments which support the implementation of computer-lab and its maintenance [2].

Unfortunately, the change becomes an almost impossible task due to the lack of economic resources sufficient to

Manuscript received May 10, 2013; revise July 18, 2013

The authors are with the Network and Operating System at Escuela Superior Politécnica del Litoral (ESPOL) (e-mail: jemunoz@fiec.espol.edu.ec). provide state of the art computing facilities required for its implementation. Even if we don't take into account the legal mandate, it's obvious that the current generation of children will need technology working environment. As a possible solution for those limitations, need of technology education and lack of resources, desktop virtualization presents itself as a solution using low cost hardware and open source tools, especially in schools and community centers. This relatively new technology increments the education quality, helping the students and the teachers without a great amount of monetary investment. Each virtual desktop is equipped with several interactive applications that reinforce the curriculum contents and the children can access them quickly and easily from a thin client at home, at the library, or at the community centre, using the deployed network.

\section{DeskTOP ViRTUALIZATION}

Desktop virtualization is the concept of isolating a logical operating system (OS) instance from the client access while customers experience the same as in a regular desktop. Users can log in to get their personal desktops through the network with any devices at any time and any place [3], and use the same applications and the same graphic environment, making the virtualization process a transparent one. The architecture of Virtual Desktop Infrastructure (VDI) consists in installing virtual infrastructure, over it Virtual machines are deployed whit the operating systems, but separating each desktop to a specific client as we see in Fig. 1.

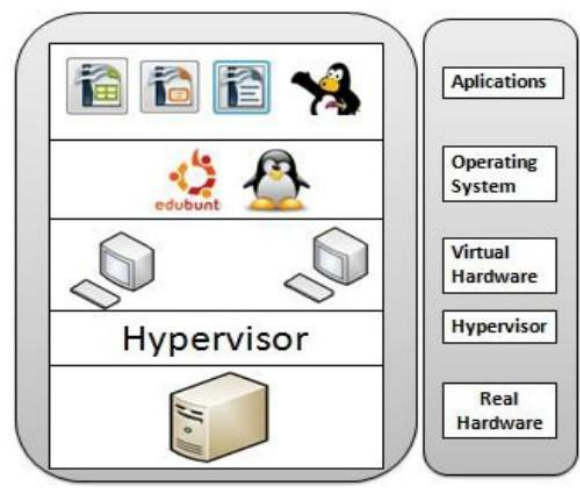

Fig. 1. Desktop Virtualization Infrastructure.

\section{A. Advantages}

Desktop virtualization has been very successful due to the benefits it offers in comparison with the traditional (stand alone PC) implementations. First of all, Desktop virtualization allows reusing older hardware saving money and contributing to the environmental conservation by consuming less energy and recycling components. Desktop 
virtualization also permits a more scalable and flexible infrastructure; if the institution number of users increases, the administrator simply creates the virtual machine's profiles without hardware investment. Since Desktop virtualization has a centralized administration, its management and maintenance is easier, reflecting in a more productive IT department, and avoiding time loss due to workstations problems. Security is also a very important feature for this architecture since users profiles are created centrally and each profile has assigned permissions in a single environment. Moreover so that the same computer would hold users that work independently without affecting each other resources can be optimized.

\section{B. Disadvantages}

The VDI technology has also some disadvantages. Since it handles everything in a centralized environment, usually on a unique physical machine, there is a single point of failure for the system; if this specific equipment has some physical problem, all stations would be useless and the entire infrastructure would be unusable. Another drawback is the deep relation between the network resources and the system performance; if the implementation is done over an old network infrastructure without taking contingency measures, the system performance would be poor.

\section{Poll Results}

\section{Polls Results Ofimatic Tools}

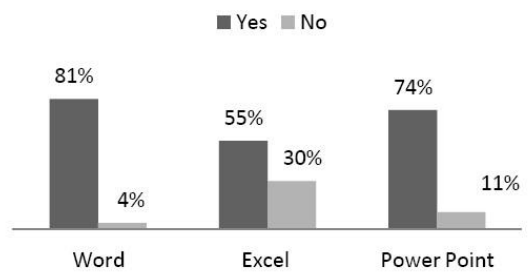

Fig. 2. Polls results Ofimatic tools.

\section{Poll Results PDF Reader}

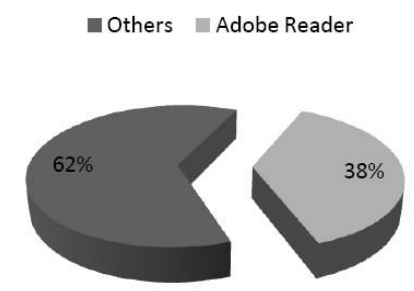

Fig. 3. Polls results pdf reader.

Polls were performed in different public schools in San Vicente-Manabí, to $7^{\text {th }}$ grade students. Simple questions were used to determine which computer tools they knew, using Microsoft office as a reference since it's the most common office suite used in Ecuador. The results showed that most of the children used at least six of the seven Ofimatic tools presented. These tools were from the Microsoft office and, as we can see in Fig. 2, approximately $81 \%$ of the children answered positively when asked about Microsoft word and similar tools from the suite. When the students were asked about Adobe Reader, a pdf documents viewer, most children (around 60\%) didn't know or have never used it in schools. All the students knew or had used at least one web browser; they named three well known programs as shown in Fig. 6. Some of the other pools results can be seen in Fig. 3 to Fig. 5.

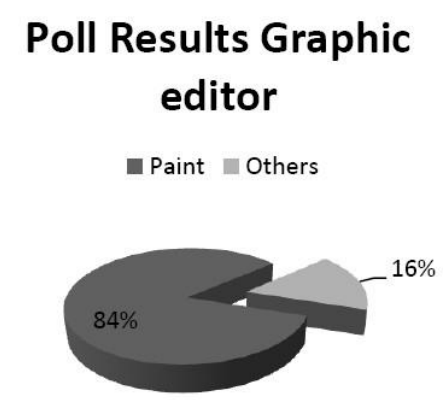

Fig. 4. Polls results graphic editor.

\section{Poll Results Encyclopedia}

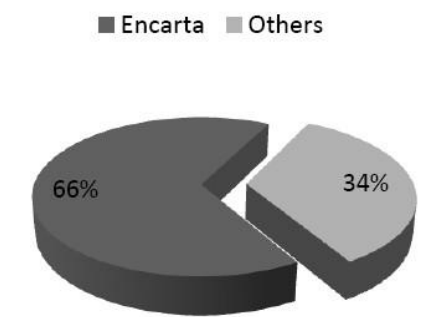

Fig. 5. Polls results encyclopedia.

\section{Poll Results Browser}

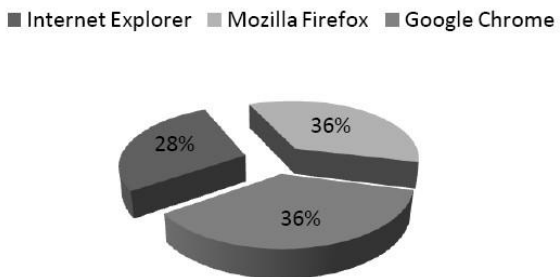

Fig. 6. Polls results browser.

\section{LABORATORY TEST}

Based on the information provided by the students through the polls, we developed different hardware and software performance test for the virtualized desktop environments. At the laboratory, we installed and configured a VDI in a HP ProLiant DL120 server, and three desktop computers for testing purposed. We can see in Fig. 7 the environment created for these tests. The results from these test helped us to determine the performance and scalability of the proposed system using the VDI chosen for the elementary education environment in which the solution was going to be implemented. Before and during the test, we identified several key factors for measuring the system performance, such as RAM memory, hard disk and processor usage percentage, application handle and network interface load, traffic and congestion that affected the infrastructure performance and the final users perception of the environment performance. Applications were selected and 
the legal requirements of the local legislation. Additionally, we measured the network performance in order to establish the optimal network conditions for our implementation.

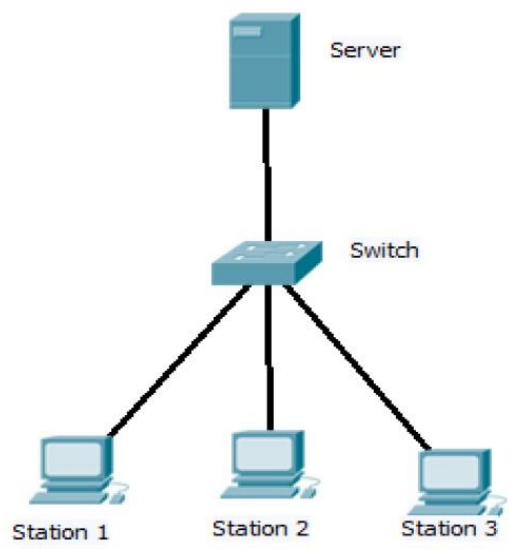

Fig. 7. Laboratory environment.

\section{SOFTWARE}

Nowadays, there are several desktop virtualization software solutions with different kinds of licenses such as proprietary, free, close source and open source. Some of solutions are widely used in education and were our best option. The Linux Terminal Server Project (LTSP) is a virtualization software based on a Linux distribution successfully implemented in educational institutions that do not have sufficient resources to invest in new technology equipment [4]. LTSP enables reusing hardware and allows users to work with open source tools such as OpenOffice and LibreOffice ofimatics suites. LTSP can also be implemented using the Edubuntu distribution, which is designed for schools focusing in providing an environment that enables an easy learning experience to children [4].

\section{HARDWARE}

The selected hardware had to suitable for the specific deployment in which we were interested. In our case, the deployment was going to be a elementary adult school in Manabi. One of our first tasks in the lab was to check the requirements of the chosen virtualization software (LTSP). For the first group of the laboratory environment tests, we used an HP ProLiant DL120 Server as a central server and some old PCs for the user's access. For a second scenario (with a different set of computers over which the LTSP was ran) we used a PC with the same kind of hardware (Intel core 2 Duo 3.4ghz, 2GB RAM, and 250 GB hard Disk) that you can find in a home PC as central server and the same old PCs that we used in previous experiments for user's access. This last scenario accurately simulated the current Ecuadorian educational institutions reality, some old and only a few new PCs, and although we could not perform processes that demand high-performance hardware the used PCs and LTSP infrastructure allowed the use of basic office tools.

\section{NETWORK CONSIDERATIONS}

One of the most important elements for implementing a VDI is the network. The way of connecting the machines and the type of cables used for these links will define the system performance; the platform of the institution should be optimized for this communication.

\section{A. Network Resources}

The first component for network optimization is to determine the real amount of resources that our machines are using in terms of RAM, CPU, storage and network traffic. In this way, we can calculate the real network consumption and the available resources for our system. For measuring this consumption we used several performance measurement tools, and depending on the application that we decided to implement, the tests took from hours to days. After the performance evaluation, we analyze the data and determined the minimum requirements.

\section{B. Network Interface}

It is also important to have an adequate number of network cards in the virtualization sever since through them all the data and machines states of the users would be transported to the clients. A single card can support multiple stations but depending on the amount of clients this link could be consider a network bottleneck that degrades the network performance. After determining the real resources available for a single server network interface, we can calculate the number of network cards to be used in our implementation based in the amount of users that we expect.

\section{Cable's Category}

TABLE I: COMPARISON BETWEEN THE DIFFERENT WIRING STANDARDS [6]

\begin{tabular}{|l|c|c|c|c|c|}
\hline & $\begin{array}{c}\text { Cat 5e } \\
\text { Class D }\end{array}$ & $\begin{array}{c}\text { Cat 6 } \\
\text { Class E }\end{array}$ & $\begin{array}{c}\text { Cat 6 } \\
\text { Class } \\
\text { EA }\end{array}$ & Class F & $\begin{array}{c}\text { Class } \\
\text { FA }\end{array}$ \\
\hline $\begin{array}{l}\text { Frequency } \\
\text { Range }\end{array}$ & $1-100$ & $1-250$ & $1-500$ & $1-600$ & $1-1000$ \\
\hline $\begin{array}{l}\text { Insertion } \\
\text { Loss (dB) }\end{array}$ & 24.0 & $21.3(21.7)$ & 20.9 & 20.8 & 20.3 \\
\hline $\begin{array}{l}\text { NEXT } \\
\text { Loss (dB) }\end{array}$ & 30.1 & 39.9 & 39.9 & 62.9 & 65.0 \\
\hline $\begin{array}{l}\text { PSNEXT } \\
\text { Loss (dB) }\end{array}$ & 27.1 & 37.1 & 37.1 & 59.9 & 62.0 \\
\hline $\begin{array}{l}\text { Return } \\
\text { Loss (dB) }\end{array}$ & 10.0 & 12.0 & 12.0 & 12.0 & 12.0 \\
\hline $\begin{array}{l}\text { Delay } \\
\text { Skew (ns) }\end{array}$ & 50 & 50 & 50 & 30 & 30 \\
\hline
\end{tabular}

The cable's category selection is fundamental for the network performance, since the cables are the low level basic link between the central server and the final users. Depending on the cable's category, our network has a maximum bandwidth, transfer rate, delay and loss; which are important features for data transmission. In all the tests, we used a wired network with Category 5e cables; this category has been enough for the lab environment, but the greater amount of users will demand a higher bandwidth and so on a real environment could need category 6 cables. In our case we use different data transmission rates in the switch; Fast Ethernet $(10 / 100 \mathrm{Mbps})$ interfaces to the client stations and Gigabit Ethernet (100/1000 Mbps) to the server, because the server link handles the traffic from/to all the users and it needs more transfer capacity. Table I shows the comparison of the cabling standards in terms of frequency, delay and loss that can affect the data transmission rate and the network performance; this is the minimum information required to 
determine the cable's category that should be used for a specific network implementation.

\section{SCHOOL DEPLOYMENT}

We deployed this solution in "Humberto Garcia Delgado" Adult Education Primary School which was chosen from the several schools that helped us with the initial pools. We selected this particular one due to its principal predisposition for being part of the pilot implementation and its lab needs. In this school students didn't have any real computer laboratory. The students could only access four average computers without connection between them or to the Internet as you can see in Fig. 8. They didn't have a network infrastructure and the computers had an outdated Operating System that came by default when they were purchased. In Table II we can appreciate the characteristics that the computer had in detail.

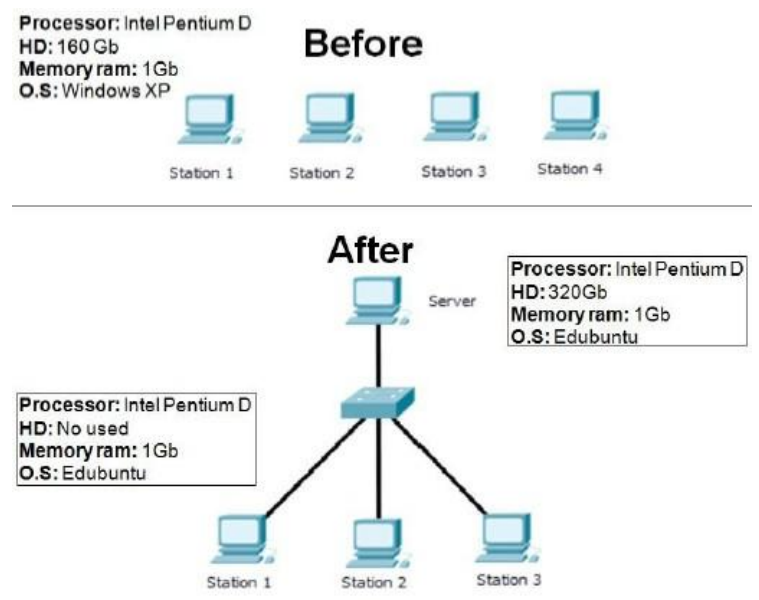

Fig. 8. Network infrastructure - before and after.

TABLE II: INITIAL NETWORK INFRASTRUCTURE

\begin{tabular}{|l|l|}
\hline \multicolumn{1}{|c|}{ Characteristics } & \multicolumn{1}{c|}{ Value } \\
\hline Network Connection & No network connection \\
\hline Operating System & Windows XP \\
\hline RAM Memory & $1 \mathrm{~GB}$ \\
\hline Hard Disk & $160 \mathrm{~GB}$ \\
\hline Processor & Pentium Dual Core \\
\hline
\end{tabular}

TABLE III: FINAL NETWORK INFRASTRUCTURE

\begin{tabular}{|l|l|}
\hline \multicolumn{1}{|c|}{ Characteristics } & \multicolumn{1}{c|}{ Value } \\
\hline Network Connection & Network connection \\
\hline Processor & Pentium Dual Core \\
\hline RAM Memory & $1 \mathrm{~GB}$ \\
\hline Hard Disk & No used \\
\hline Operating System & Ubuntu 12.04 \\
\hline
\end{tabular}

After analyzed the initial situation, we built a network infrastructure in the school, with the school's authorities collaboration, we implemented a small network based in sever-client with Edubuntu installed in the main computer and the clients could access the environment through the network. We changed the operating system from Windows $\mathrm{XP}$ to Ubuntu and installed the package Edubuntu that already contained the educational applications. In Table III we can see the characteristics of the implemented network. In
Fig. 8 we can see the network infrastructure changed.

\section{Cost Evaluation}

The cost evaluation was based in the prices, using the four possible environments to implement the laboratories; we evaluated the hardware and considered four options (Table IV). The first we used a new server (HP ProLiant DL120) and six old desktop computers (Pentium III), the second we used a new server (Sun Fire X2200 M2) and six thin clients (Sun ray 2), the third we used six new desktop computers (Xtratech Intel ci7 3.4ghz, 8gb, 2tb, windows 8), the fourth we used a new server (HP ProLiant DL120) and six new desktop computers (Xtratech model). During the evaluation of the software we considered the next options (Table V). The first was evaluated the tools that are paid and the second similar tools but they are free. Finally we considered evaluating hardware maintenance for the four options (Table VI). The first we evaluate hardware maintenance for a new server (HP ProLiant DL120) and six old desktop computers (Pentium III), the second we evaluated hardware maintenance for a new server (Sun Fire X2200 M2) and six thin clients (Sun ray 2 ), the third we evaluated hardware maintenance for six new desktop computers (Xtratech model) the fourth we evaluated hardware maintenance for a new server (HP ProLiant DL120) and six new desktop computers (clones).

TABLE IV: COST OF HARDWARE FOR SIX STATION COMPUTER LABORATORY AND ONE SERVER

\begin{tabular}{|c|c|}
\hline Hardware options & Cost \\
\hline New server and old desktop computers & $\$ 1.862,78$ \\
\hline New server and thin client & $\$ 2.751,58$ \\
\hline New desktop computers & $\$ 6.172,62$ \\
\hline New server and new desktop computers & $\$ 8.035,40$ \\
\hline
\end{tabular}

TABLE V: COST OF SOFTWARE FOR SIX STATION COMPUTER LABORATORY AND ONE SERVER

\begin{tabular}{|l|r|}
\hline \multicolumn{1}{|c|}{ Software options } & Cost \\
\hline $\begin{array}{l}\text { New machines that use a Windows operating } \\
\text { system }\end{array}$ & $\$ 1.015,26$ \\
\hline $\begin{array}{l}\text { New machines that use an open source operating } \\
\text { system }\end{array}$ & $\$ 0,00$ \\
\hline Office software for windows & $\$ 1.403,31$ \\
\hline Software open source office suite & $\$ 0,00$ \\
\hline
\end{tabular}

TABLE IV: ANNUAL COST OF MAINTENANCE FOR SIX STATION COMPUTER LABORATORY AND ONE SERVER

\begin{tabular}{|c|c|}
\hline Maintenance options & Cost \\
\hline New server and old desktop computers & $\$ 550,00$ \\
\hline New server and thin client & $\$ 1.575,79$ \\
\hline New desktop computers & $\$ 720$ \\
\hline New server and new desktop computers & $\$ 1.270,00$ \\
\hline
\end{tabular}

\section{CONClusion}

Desktop virtualization is a good solution to implement computer laboratories in schools and educational centers that do not have the resources to invest in new equipment due to the reuse of old computers as client stations and a low-cost computer as a server.

Based on the poll results, the cost analysis and the 
laboratory tests, the best hardware combination for implementing a VDI in our medium is a modern PC new server and several old desktop computers as user's clients. This design can be adapted to the schools requirements and budgets.

Since system management and maintenance are limited mainly to the "server", the solution presents a lower cost compared to other implementations.

According to Higgins all [5] technology in the education is a catalyst for change; it depends on the students and the teachers to use this "change" for improving in learning terms. This project has a great impact in order to ensure that children develop knowledge in an accurate environment that facilitates the change to the new society perspective, but the technology itself cannot be seen as a magical solution for increasing the education quality.

Based on all the previous reasons, VDI allows students to have a quality education despite their limited resources and the national economic situation saving the gap between first world countries and developing ones.

\section{ACKNOWLEDGMENT}

We thank the children and teachers of San Vicente-Manabí schools, which allowed us access and provided us with important information about their computer's use and preferences without which, the project would have been impossible and unjustified. We also thank Prof. Patricia Chavez, Telematics Engineering Program Coordinator at ESPOL without help, knowledge and patience the task would have been more difficult to accomplish.

\section{REFERENCES}

[1] Constitución de la República del Ecuador, chapter 2, 3rd subsection, article 16, subsection 2 available.

[2] H. Slay, I. Siebörger, and C. Hodgkinson, "An investigation into the use of interactive whiteboards in South African Schools," in Proc. IADIS International Conference Interfaces and Human Computer Interaction, South Africa, 2007.

[3] L. Yan, "Development and application of desktop virtualization technology," in Proc. 2011 IEEE 3rd International Conference on
Communication Software and Networks (ICCSN), Xi'an, China, 2011 pp. 326-329.

[4] R. M. Sierra and S. K. Vega, "Análisis, diseño e implementación de un proyecto de servidor de terminales Linux (LTSP) para el centro de computo de la Unidad Educativa José Luis Tamayo, bajo la plataforma GNU/Linux Edubuntu con aplicaciones de software libre," B. S. dissertation, Facultad de Ingeniería., Politécnica Salesiana Univ., Quito, Ecuador, 2012.

[5] S. Higgins, Z. Xiao, and M Katsipataki. (November 2012). The impact of digital technology on learning: A summary for the education endowment foundation, Durham University. [Online]. Available: http://educationendowmentfoundation.org.uk/

[6] V. Rybinsky. Structured future: Cabling standards and specifications from cat 5e to 7a. Industrial Ethernet Book. [Online]. Available: http://www.iebmedia.com/

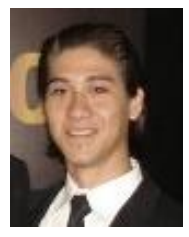

José Enrique Muñoz Arcentales was born in Guayaquil-Ecuador, on February $28^{\text {th }} 1988$. He is currently study a BS. in network and operating system at ESPOL. He worked in "Fundación Terminal Terrestre" as Technical support in 2010 in Guayaquil-Ecuador; he worked as a lab assistant of the distributed system lab. He's currently member of "Célula Microsoft ESPOL".

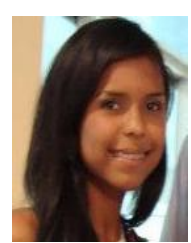

Sara Estefania Zambrano Vite was born in Guayaquil-Ecuador, on June $3^{\text {rd }} 1992$. She is currently study a BS. in network and operating system at ESPOL, she worked in "Fundación Terminal Terrestre" as Technical support in 2010 in Guayaquil-Ecuador; she currently works as a lab assistant of the distributed system lab. She's member of "Célula Microsoft ESPOL”.

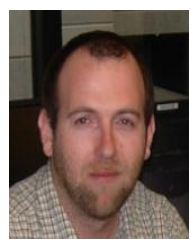

Prof. Ignacio Marin-Garcia was born in Logroño, Spain on September $24^{\text {th }} 1975$. He received his bachelor in Science Engineering Technology degree in 2003 and his Master Science in Information Systems in 2006, both from Northeastern University. He currently works as Full-time assistant professor at Telematics Engineering department at Escuela Superior Politécnica del Litoral (ESPOL). His research interests include high performance computing, parallel computing, virtualization, security and education. He has been member of ACM since 2004 and IEEE since 2003 (computer society and standard association). HE worked as a Junior Researcher and Teaching Assistant at the "ITEST Robotics" project (NSF 0423059). 